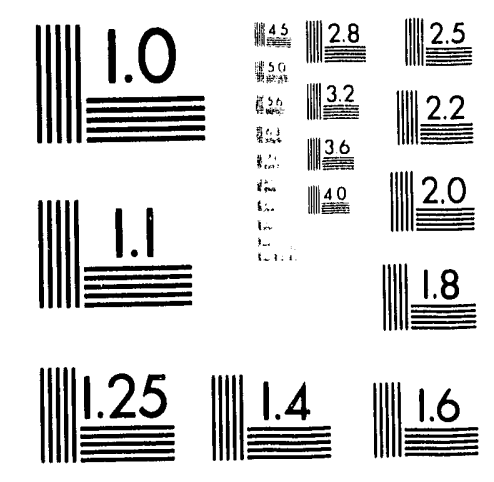



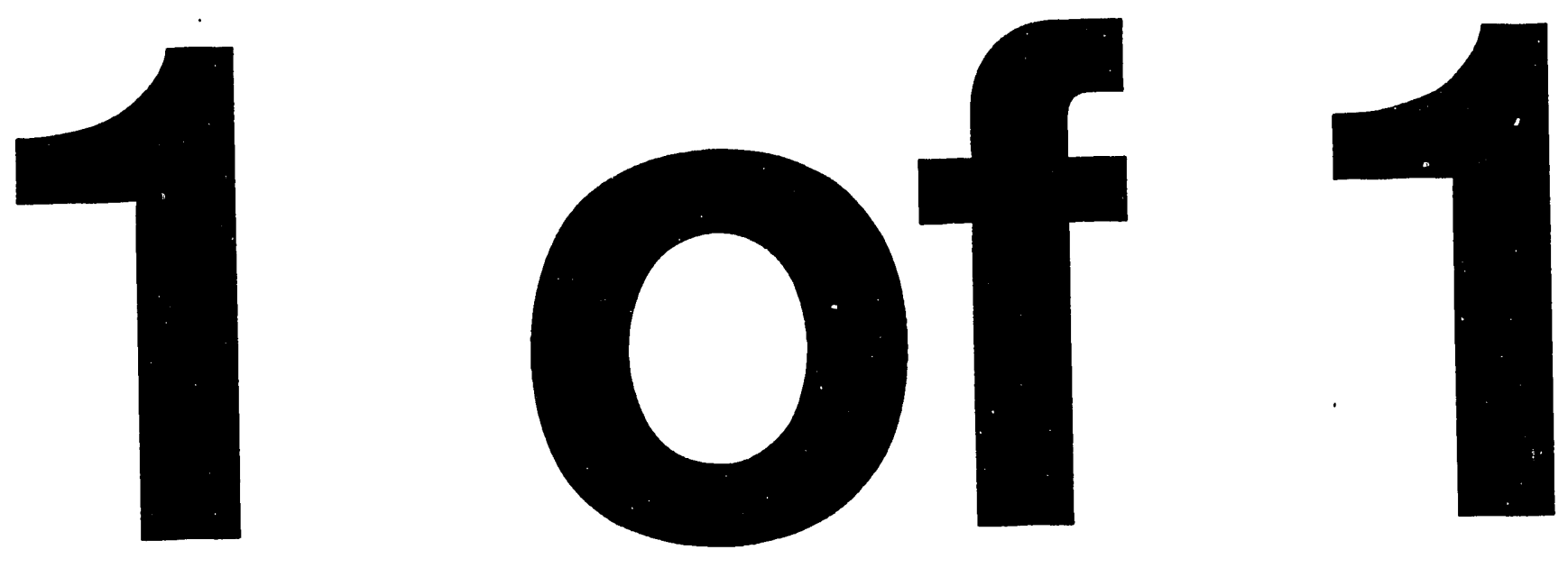
SAND94-8200

Unlimited Release

Printed October 1993

\title{
H1501 Test Summary and Certification Report (U)
}

\author{
*E. F. Kibalo \\ Systems Engineering Department III \\ Sandia National Laboratories/California
}

\begin{abstract}
The H1501 Transportation Accident Resistant Container (TARC) was developed using the previously completed design and hardware from the Helicopter Accident Resistant Container (HARC) program. This report documents the test program used to certify the capability of the $\mathrm{H} 1501$ for shipping W48 and W79 war reserve projectiles. The program includes new containers built by Associated Machine Technology (AMT) and older HARC containers that had wheels and tie-down points added and were recertified after years of storage as H1501 containers.

The 1973-76 HARC development program was extremely successful with a demonstration of impact and fire capability that significantly exceeded the design requirements of 100 fps impact velocity and 90 minutes of fire protection. In 1990-91 two TARC test units were subjected to accelerated drop test: followed by fuel fire burn tests with the objective of increasing the original limits. These tests were successful in confirming the design margin of the $\mathrm{H} 1501$ to exceed $163 \mathrm{fps}$ impact followed by 2 hours of fuel fire. H1501 containers were also subjected to vibration and shock tests for normal transportation environments for the W48 and W79. The results of these tests confirmed that the requirements were met for both systems.
\end{abstract}

* E. F. Kibalo is and Allied-Signal employee on contract to Sandia National Laboratories.

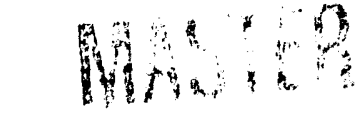




\section{CONTENTS}

BACKGROUND
Scale Model Impact Test
$\quad$ Scale Model Fuel Burn
Sympathetic Detonation
Prototype Impact Test
Prototype Fuel Burn
"Test Units A and B"
H1501 "Test Unit A" Fuel Burn
H1501 "Test Unit B" Fuel Burn
H1501 With W48 Trainer Vibration Test




\section{ILLUSTRATIONS}

No.

1. Figure 1. Helicopter Accident Resistant Container

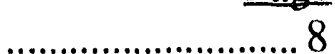

2. Figure 2. "Test Unit A" Container Accelerations

3. Figure 3. "Test Unit B" W79 Projectile Acceleration

4. Figure 4. Internal Temperatures from H1501 "Test Unit B"

\section{TABLES}

No.

1. Table 1. H1501 W48 Testing Sequence

2. Table 2. H1501 W48 Random Vibration Table

3. Table 3. CH-47 Helicopter Discrete Frequency Excitation

Amplitudes

4. Table 4. H1501/W49 Testing Sequence

5. Table 5. H1501 /W79 Random Vibration Spectra 22

6. Table 6. H1501/W79 Sine Dwell Testing 


\title{
HI501 TEST SUMMARY AND CERTIFICATION REPORT
}

\author{
BACKGROUND
}

The HARC program was conducted at SNL, New Mexico from 1973 through 1976. The HARC was designed to carry weapons on helicopters and prevent scattering plutonium after an impact of 100 fps followed by a 90 minute fire. Its design featured a stainless steel outer skin, redwood for impact mitigation and fire protection, and a thick aluminum inner container. See (Figure 1). Accident simulation testing in this document demonstrated that the capability of the container is really in excess of an impact of 163 fps followed by a two hour fuel fire.

The redwood has two important functions, to absorb impact energy by crushing and to insulate the weapon from heat in a fire. When starved for oxygen, it forms a char which also is a good insulator. The process of charring releases gasses that help to carry heat out of the container.

The stainless steel outer skin provides a tough shell that holds the container together after an impact and keeps air off the redwood in a fire. Stainless steel is used because of its great ductility which allows it to stretch, bend, and buckle but will not easily tear open. The outer skin has several small holes to let the gasses vent when the redwood chars. There are four lifting shackles attached to the outer skin.

The thick-walled inner container is rigid to shield the weapon from the large deformations experienced by the redwood and outer skin. It has a stiff, bolted on door. A specially designed insert or shipping container assembly holds the weapon in the inner container (P/N 249100 for the W48 and 249228 for the W79).

The container is mounted on an aluminum base (the bolster) to make it easier to handle. Tie down rings, adjustable casters and openings for forklift tines were added to the HARC design. With these new design additions, the HARC became the H1501.

The original HARC containers were built by Bendix KCD and shipped to SNL, New Mexico. Twelve years of storage outside in Albuquerque, New Mexico, resulted in the swelling of the redwood on the exterior door and that redwood was replaced. All the other redwood was protected by the epoxy bonding and showed no signs of swelling. The redwood on the door now receives the same epoxy treatment as all the other redwood used in the container. Also, a bolster, with hardware was added to each container plus the internal supports were fabricated for the W48 and W79.

In August 1990 an order was placed with AMT for five H1501 units to reestablish manufacturing capability. These units were delivered to SNL, California in 1991. 


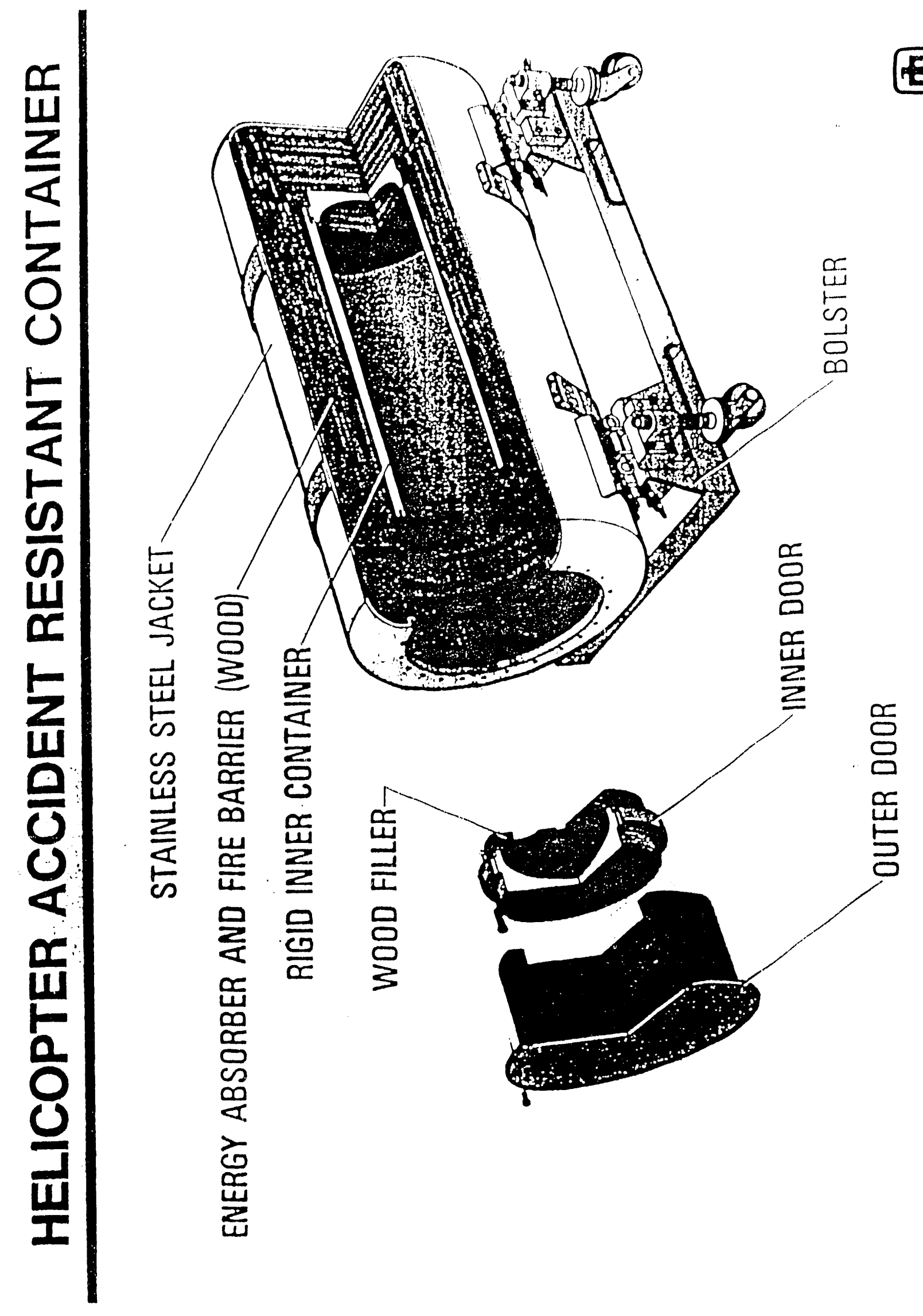

田

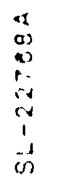




\section{TESTING}

The normal environment tests (vibration) are used to certify that the weapon will not be damaged during shipment while the abnormal environment tests (drop and fuel burn) can only give an approximate result of what would happen if a crash were to actually occur. The following tests were conducted for the HARC followed by the H1501.

Scale model impact, fuel burn and sympathetic detonation testing was conducted in $1974.2,3$ These tests helped to determine the eventual configuration of the original HARC.

After the HARC was reconfigured into the H1501, vibration tests were conducted to qualify the H1501 for nomal transportation use. These vibration tests occurred in 1987 for the W48 and in 1989 for the W79 and covered the range of helicopter, fixed wing cargo aircraft and ground transportation that could ship the container.

In 1990, H1501 "Test Unit A" was dropped twice and a few weeks later burned in a fuel fire. The information gathered from this test was used to determine the parameters for "Test Unit B", which was dropped and fuel fire burned in 1991.

\section{Scale Model Impact Test}

In 1974 an extensive scale model impact test sequence was conducted on a 35 foot centrifuge. Over 80 models were impacted against a massive steel target at various controlled impact angles and velocities. 4

These tests were quite successful. It was found that welded construction for the outer case was definitely preferable over riveted construction and that the longitudinal wood grain orientation was preferable. In addition, these tests indicated that the basic design parameters and primary sizing assumptions were correct.

\section{Scale Model Fuel Burn}

In 1974 two previously impact tested $3 / 8$ scale models were exposed to a fuel fire of thirty-three minutes at $1850^{\circ} \mathrm{F}$ which approximates three-eighths of the 90 minutes duration full scale fire. A scaled duration fire test is meaningful because the models maintain a scaled surface/volume relationship and, for a given material such as redwood, the char velocity is relatively constant.

The models were sectioned with a band saw to determine the char depths from the burn. The unit that had the open area by the door charred deeply and in some areas the char appeared to reach the surface of the container. However, at the opposite end the char was less than half the thickness of the redwood. The second unit had a seam exposed and the redwood in that area charred to the inner container. The passive temperature indicators recorded $220^{\circ} \mathrm{F}$ to $240^{\circ} \mathrm{F}$ inside the inner container. This was a low temperature for the large amount of redwood exposed and illustrated the insulative properties of charred redwood. 


\section{Sympathetic Detonation}

In 1972 a series of sympathetic detonation tests were conducted on three $3 / 8$ scale models during development testing of the HARC. The tests concluded with the three models exposed to an explosion using four times the amount of explosives in each W48. None of the aluminum cylinders on the three model HARCs were penetrated on this test. Therefore, this overtest demonstrated that the detonation of the explosive of a W48 in a HARC will not detonate the explosive of a W48 in an adjacent HARC.

\section{Prototype Impact Test}

In 1975-76 nine full-scale HARC prototype units, with payloads, were impacted at various angles at $100 \mathrm{fps}$. One unit was impacted twice for a total of $10 \mathrm{impacts}$. The units were pulled into a 4 -inch thick steel plate anchored to a reinforced concrete block. These units were impacted in five different orientations: full side-on, closed-end, doorend, 45 degree angle on door-end, and 3() degree angle on door-end.

No unusual external damage occurred on any impact and the deformations were proportional to the impact deformations of the scaled models which had been tested previously. No deformation or cracking of the inner container was found, although the inner door seal was destroyed on one drop. Upon investigation, it was found that the effective thread engagement of the inner door bolts was slightly below one bolt diameter. This situation was corrected by using longer bolts which provided the recommended 2 1/2 bolt diameter engagement.

\section{Prototype Fuel Burn}

In 1976 two of the above full-scale HARC prototype units were subjected to a 90 minute fuel fire test. One unit was previously subjected to a 45 degree $100 \mathrm{fps}$ impact. The other unit had not been impacted.

For both of these units, postburn measurements showed that the redwood acted as an insulator as less than half of the redwood thickness charred. The passive monitoring devices indicated that the maximum inner container temperature was $120^{\circ} \mathrm{F}$.

\section{"Test Units A and B"}

In 1990 a series of tests was planned to assess the design margin and extend the certified capability that the H1501 can protect projectiles during and after a crash.

The test objectives were to:

1. prove the H1501 capability to survive impacts greater than $120 \mathrm{fps}$.

2. prove the H1501 capability to withstand fires longer than 90 minutes.

3. compare a 15-year old HARC to a new H1501.

4. gather data which may be used in risk assessments.

5. qualify the H1501 to safely ship the W79.

"Test Unit A" was a refurbished unit from the group of 22 that remained from the HARC, while "Test Unit B" was a new unit made by AMT. Each test unit contained a mock W79 and its insert kit. Initially, more tests, involving additional units, were anticipated but, because the results were excellent and confinmed analytical predictions, additional tests were unnecessary. 


\section{0) "Tess Unit A" Impiact Tests}

In 109() this unit was subjected to two sequential drops on a simulated runway concrete target: an impact velocity of $147 \mathrm{fps}$ via a flat drop on its bottom and $105 \mathrm{fps}$ on the door end. The test unit survived both drops with no tears or openings in the outer stainless steel skin. For the flat drop, the acceleration pulse for the H15()1 was approximately $1800 \mathrm{~g}$ 's peak with a pulse width of $8 \mathrm{msec}$, while the pulse for the end drop was approximately $1(0)(0 \mathrm{~g}$ 's peak and $6 \mathrm{msec}$. Figure 2 shows acceleration plots for both lests, as measured at the container imner cylinder. Neither of the impacts would have caused a war reserve 679 to scatter radioactive material. 

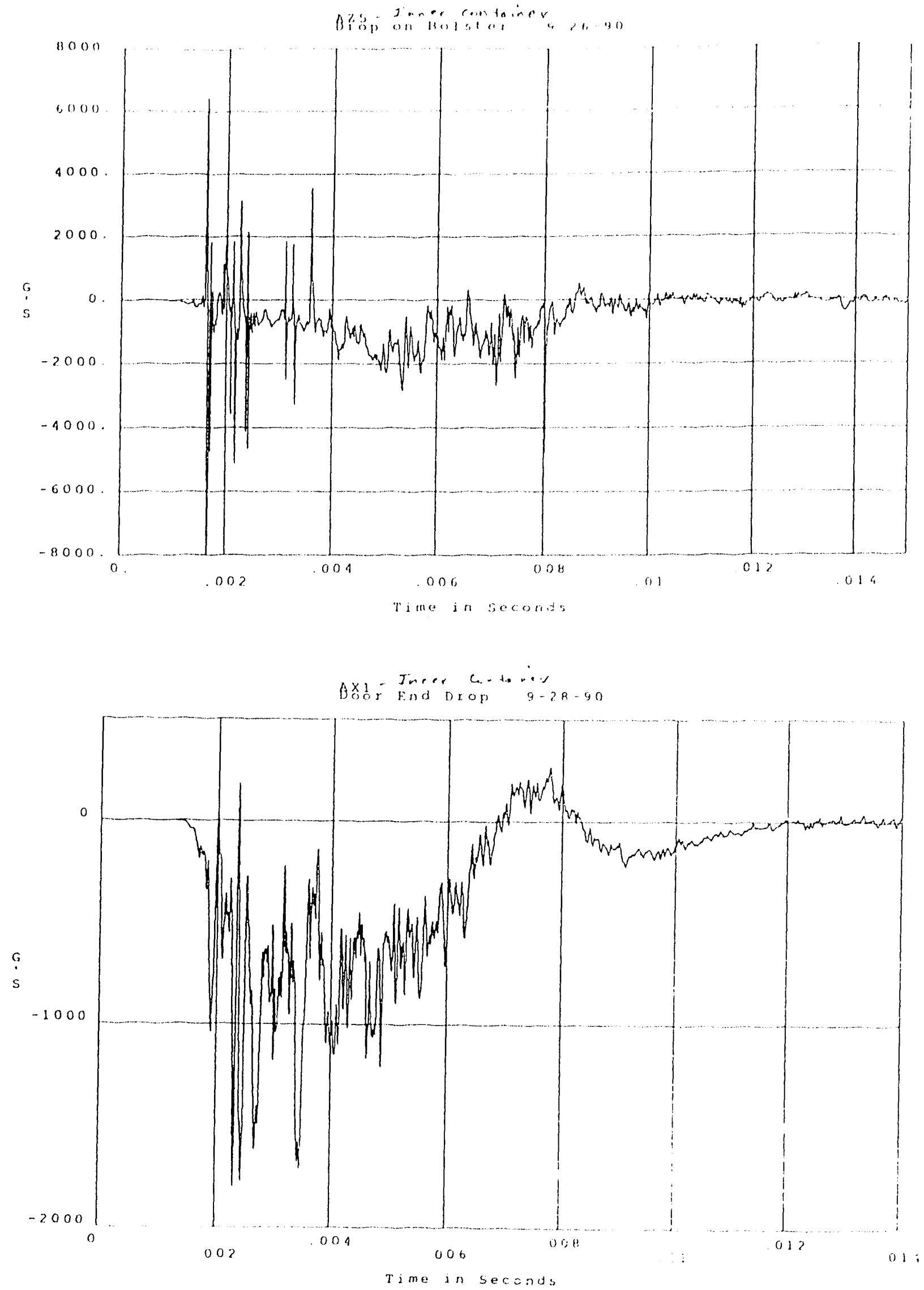

Figure 2. "Test Unit $A$ " Container Accelerations, 147 fps Flat Impact (upper) and 105 fps Door End Impact (lower) 
H150) "less Unit A" Fuel Burn

After the two impacts described above, "Test Unit A" was originally scheduled for a two hour fuel fire burn test, which would have been longer than any previous burn test. However, twenty-five minutes into this test the wind shifted and, at times, little of the fire was directly on the unit. Therefore, the test was extended an additional thirty minutes and the total burn time was $21 / 2$ hours.

Within minutes of the start of the test, the vent holes in the skin of the 11501 released gasses from the redwood inside as per design. At times during the test, flames appeared to jet from these holes and especially at the large instrumentation hole, and after the test, smoke continued to be emitted as the redwood smoldered.

Twenty-four hours after the start of the test the inner cylinder temperature was approximately $165^{\circ} \mathrm{F}$. After forty-eight hours it was about $2(0)^{\circ} \mathrm{F}$. This instrumentation was then disconnected as the importance of smolder raising the temperature of the inner cylinder was not yet known. The redwood continued to smolder for nine days before it was manually extinguished. As a result, the temperature in the mock projectile reached $32)^{\circ} \mathrm{F}$ as recorded by the temperature indicating strips but the time of the peak cemperature is only known to have been between 3 and 9 days.

This first burn test of an HIS()] container identified "smolder" as a chatracteristic that needed to be considered in how the $H 1150) 1$ responds to a fire. Part of the response of the "Test Unit $A$ " to the fuel burn was caused by extra large instrumentation holes. The holes resulted from a repair of thermocouples that sheared during the second impact test that preceded the burn. Not being aware of the smokder issue, not enough consideration was given to achieving a good seal at the two instrumentation exits from the container. An improved method of sealling instrumentation exits was used on all subsequent contaners that underwent testing.

\section{1 "Test Unit B" Impalct Test}

In 1991 this unit was subjected to a lateral impact with a velocity of $163 \mathrm{fps} .5$ In roll orientation the unit was at an angle approximately $22^{\circ}$ from the upside down verticall. The target was a 16 inch thick reinforced concrete slab, simulating an airport runway.

The outer stainless steel container was punctured in two places by caster brackets. Both holes were small: the larger was $21 / 4$ inches long by $3 / 8$ inch wide by $7 / 8$ inch deep.

Radiographs were taken before and after the impact test and the results were:

1. The permanent deformation (redwood crush) was $23 / 4$ inches.

2. The $13 / 8$ inch thick inner aluminum cylinder was tightly closed.

3. The W79 stiffness mock projectile shifted within the aluminum cylinder and the fuze broke off at the fuze threads.

4. Structural integrity was maintained in the projectile pin joint area where the rocket motor is altached to the warhead.

The H1501 held up well to the impact test and provided protection to the W79 test unit, but two minor design changes were directly attributable to this drop. The caster bracket corners are now chamfered to reduce penetration of the outer stainless steel skin and the rivets that hold the security stud changed from stainless steel to aluminum. The steel 
rivets held during the drop which resulted in a small gap at the outer door. Aluminum rivets should allow the security stud to break loose and thereby reduce the gap.

The peak acceleration pulse on the projectile was approximately $1700 \mathrm{~g}$ 's and the pulse had a duration of about $5 \mathrm{msec}$. Figure 3 is an acceleration plot for the aft end of the mock W79 projectile, recorded during the "Test Unit B" impact.

\section{H1501 "Test Unit B" Fuel Burn}

Following its impact described above, "Test Unit B" was subjected to a two hour three minute fuel fire burn. Thermocouples attached te the test unit indicated the peak temperature of the inner aluminum cylinder reached $232^{\circ} \mathrm{F}$ twelve hours into the test while the projectile temperature peak was $212^{\circ} \mathrm{F}$ twenty hours into the test. See Figure 4 for temperature plots. After five days the smoldering ceased without any fire fighting activity and the test was declared finished. 


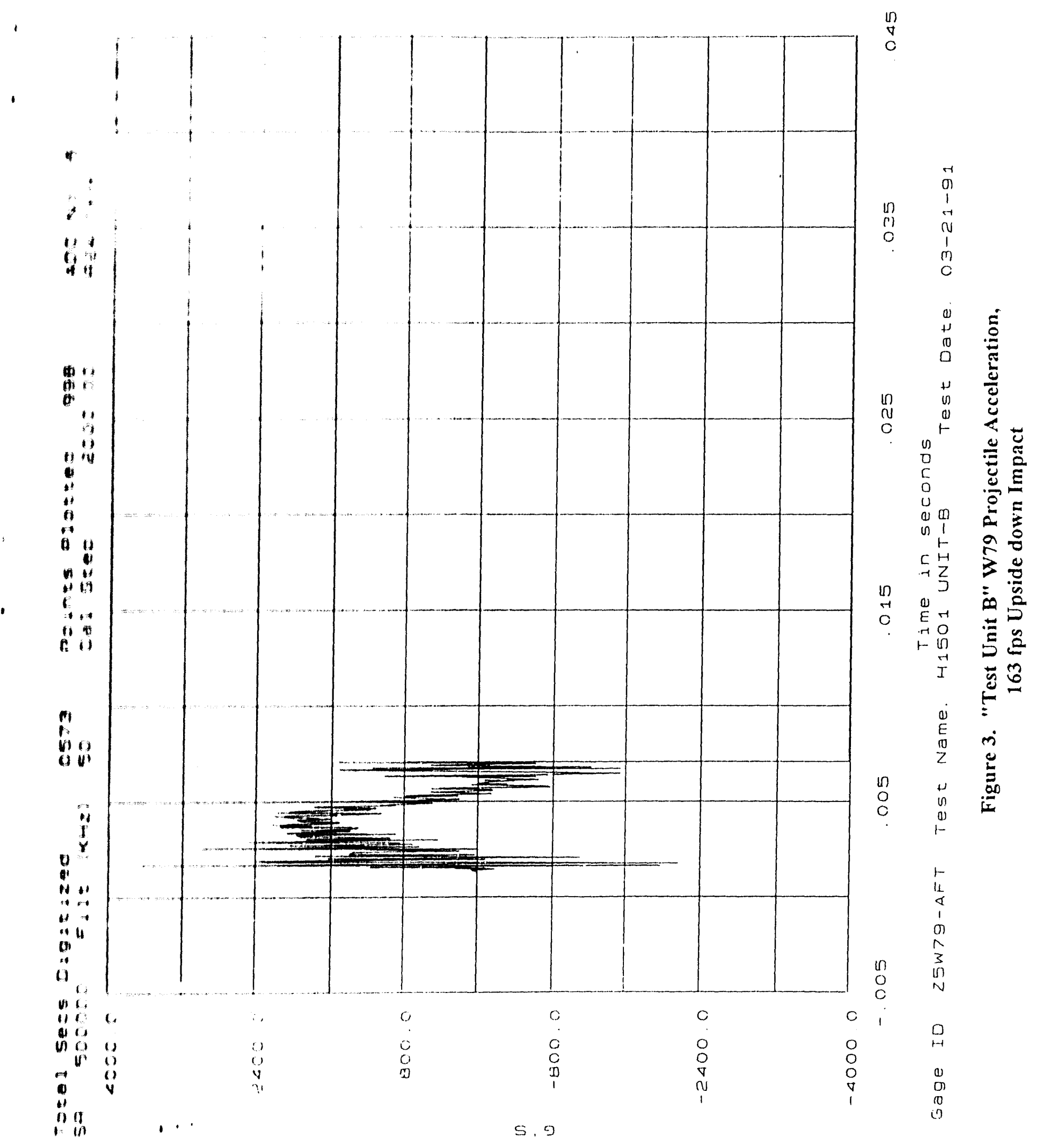




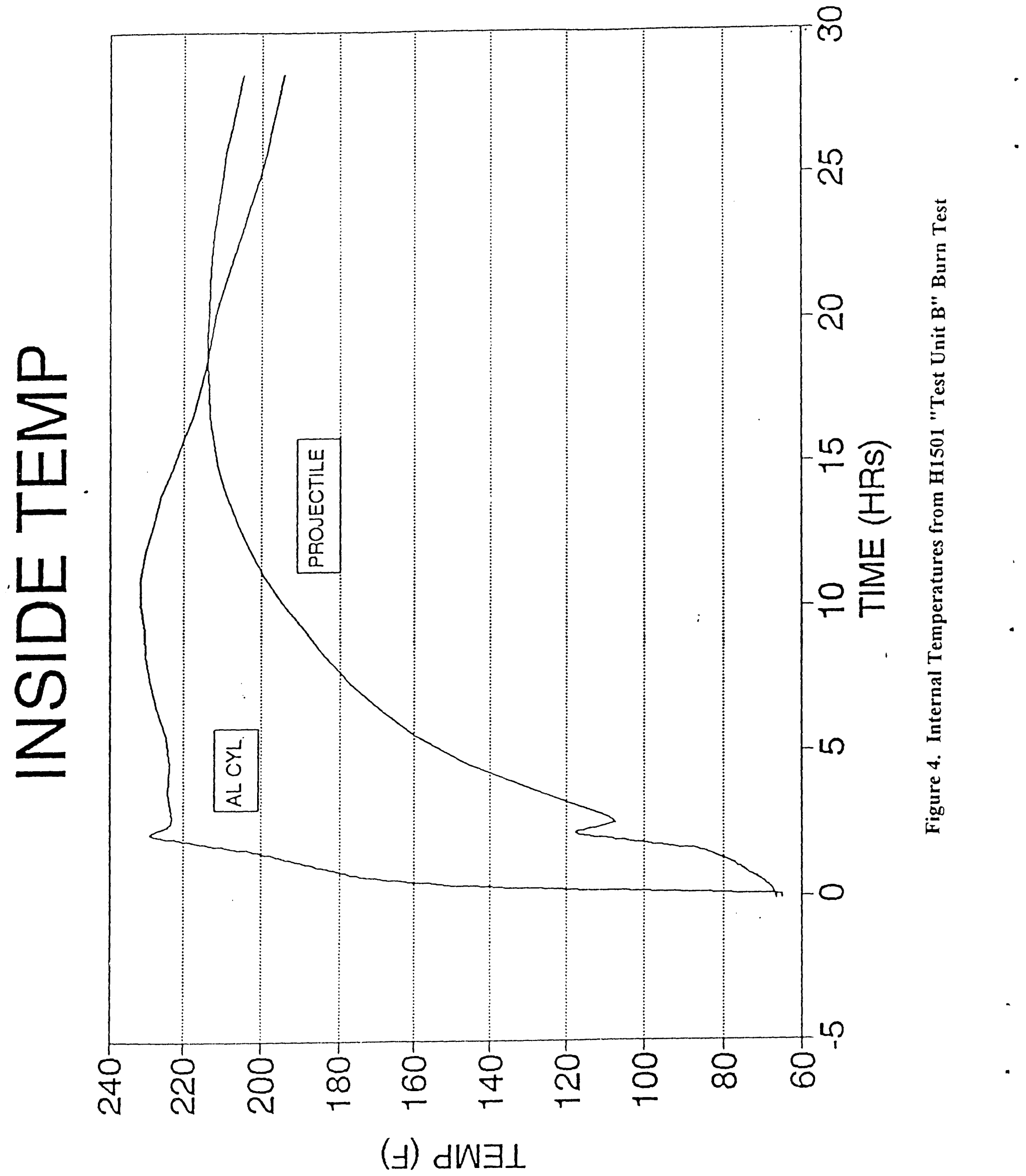




\section{H1501 With W48 Trainer Vibration Test}

In 1987 a W48 trainer artillery shell inside an $\mathrm{H} 1501$ was vibration and shock tested for normal transportation environments to compare the W48 responses in the $\mathrm{H} 1501$ with those in its war reserve shipping and storage container, the M467.6 See Table 1.

The test conditions cover the $\mathrm{CH}-47 \mathrm{C}$ and $\mathrm{CH}-47 \mathrm{D}$ helicopters, the $\mathrm{C} 130$ and $\mathrm{C} 141$ fixed wing cargo planes, and rubber-tired trucks and trailers on paved roads.

Random vibration environments were applied to the loaded $\mathrm{H} 1501$ for two minutes in each axis followed by 30 seconds of sine dwells at helicopter resonant frequencies. The spectra used for the random vibration tests represent the normal transportation environments, as agreed to by the Army, LLNL, and SNL. See Table 2.

Sine vibration tests were conducted for 84 minutes per axis, with a rate of 6 minutes per upsweep or downsweep. See Table 3.

Responses of the W48 shell to longitudinal and vertical sine vibration tests were similar to the M467 results while the transverse vibration showed higher transmissibility magnitudes in the H1501 container both for sine and random vibration tests. These higher readings are the result of the stiff redwood/steel construction of the H1501 container.

The first unit used was damaged by the clamping device as it created cracks in the weld joints along the end plate. These cracks grew during the remaining sine vibration tests but did not grow during random vibration tests. During the 18 inch drop, the fractures propagated, freeing a large portion of the end plate from the side supports. Inspection of the shipping adapter and shell did show that the mechanical use control lock device had impacted the silicone pad at the forward end of the shell, cutting it in several places.

The second and third drop shock tests (18 and 59 inches) were conducted with a "new" H1501 which had undergone only random vibration tests. Following the 59 inch drop test exterior damage, as expected, was evident. Some of the bolster welds had started to fracture and two rivets had broken off the top of the bolster.

Two design modifications were made following these tests; a slight lengthening of the shipping adapter, and enlarging the shipping adapter's U-shaped cutout around the mechanical use control lock on the forward end of the shell.

The results of these vibration and shock tests were similar to the tests on the M467 and indicate that under normal transportation conditions the reliability and/or survivability of the W48 or its components should remain unaffected during normal environments by use of the H1501. 


\section{H1501 With W79 Trainer Vibration Test}

In 1989 a W79 trainer artillery shell inside an $\mathrm{H} 1501$ was vibration and shock tested for normal transportation environments to determine if the W79 would remain unaffected during shipment in an $\mathrm{H} 1501$ on $\mathrm{CH}-47 \mathrm{C}$ and $\mathrm{CH}-47 \mathrm{D}$ helicopters, $\mathrm{r} 130$ and $\mathrm{C} 141$ fixed wing cargo planes, and rubber-tired trucks and trailers on paved roads. ${ }^{7}$

Random vibration environments were applied to the loaded H1501 for two minutes in each axis. The test spectra are defined specifically per Table 5, with each frequency representing a break point, and with linear (on log-log plot) transitions between break points.

Sine dwell tests were performed to simulate discrete resonant frequencies imported during $\mathrm{CH}-47 \mathrm{D}$ helicopter transportation. From helicopter flyarounds, it was learned that only the low frequencies introduced significant inputs onto the H1501. The massiveness of the container attenuates higher frequencies and inputs to the warhead are greatly diminished. Following each random vibration a sine dwell was applied to the same axis for about 30 seconds, which was the time needed to capture the response data. These sine dwell tests were developed for the H1501 testing to simulate the observed helicopter cargo environment and were applied to the three axes per Table 6.

Drop tests of 18 inches and 58 inches occurred when the H1501, with a W79 mass mockup shell, was dropped flat onto reinforced concrete. The 18 inch drop height would represent a short fall from, e.g., a forklift while the 58 inch drop test would represent a longer fall from e.g., a flatbed truck.

Results of these tests were compared to prior vibration and shock tests of the W79 in its usual M613 shipping and storage container. Under normal transportation conditions, the reliability and/or survivability of the W79 or its components should remain unaffected by use of the $\mathrm{H} 1501$. 


\section{TABLE 1}

\section{H1501/W48 Testing Sequence}

$\begin{array}{lll}\text { Environment } & \text { Axis } & \text { H1501 Unit Number } \\ \text { Sine Vib (ARDEC simulation) } & \text { Y (long) } & \text { SBJ1 } \\ & \text { X (trans) } & " 1 \\ \text { Drop test (18" flat, ARDEC sim) } & \mathrm{Z} & \text { SBJ1 } \\ \text { Random vib (w/30 sec sine dwells) } & \mathrm{X} & \text { SBJ2 } \\ & \mathrm{Y} & " 1 \\ \text { Drop Test (repeat of 18" flat) } & \mathrm{Z} & \text { SBJ2 } \\ \text { Drop Test (59" flat) } & \mathrm{Z} & \text { SBJ2 }\end{array}$




\section{TABLE 2}

H1501/W48 Random Vibration Table

\begin{tabular}{|c|c|c|}
\hline Axis & Frequency $(\mathrm{Hz})$ & $\operatorname{ASD}\left(G^{2} / \mathrm{Hz}\right)$ \\
\hline Transverse $(\mathrm{X})$ & $\begin{array}{r}5 \\
10 \\
15 \\
20 \\
30 \\
35 \\
200 \\
700 \\
1000 \\
1900\end{array}$ & $\begin{array}{ll}1.0 & \mathrm{E}(-4) \\
5.0 & \mathrm{E}(-4) \\
5.0 & \mathrm{E}(-4) \\
6.5 & \mathrm{E}(-4) \\
6.5 & \mathrm{E}(-4) \\
5.0 & \mathrm{E}(-4) \\
5.0 & \mathrm{E}(-4) \\
2.5 & \mathrm{E}(-3) \\
2.5 & \mathrm{E}(-3) \\
1.0 & \mathrm{E}(-4)\end{array}$ \\
\hline Longitudinal (Y) & $\begin{array}{r}5 \\
10 \\
20 \\
50 \\
120 \\
130 \\
200 \\
250 \\
10(0) \\
1900\end{array}$ & $\begin{array}{ll}1.0 & \mathrm{E}(-4) \\
6.5 & \mathrm{E}(-3) \\
6.5 & \mathrm{E}(-3) \\
1.0 & \mathrm{E}(-3) \\
1.0 & \mathrm{E}(-3) \\
3.0 & \mathrm{E}(-3) \\
3.0 & \mathrm{E}(-3) \\
1.0 & \mathrm{E}(-3) \\
1.0 & \mathrm{E}(-3) \\
1.0 & \mathrm{E}(-4)\end{array}$ \\
\hline Vertical (Z) & $\begin{array}{r}5 \\
10 \\
4() \\
100 \\
200 \\
350 \\
500 \\
1000 \\
1900\end{array}$ & $\begin{array}{ll}4.0 & \mathrm{E}(-3) \\
1.5 & \mathrm{E}(-2) \\
1.5 & \mathrm{E}(-2) \\
2.5 & \mathrm{E}(-3) \\
1.0 & \mathrm{E}(-3) \\
3.5 & \mathrm{E}(-3) \\
3.5 & \mathrm{E}(-3) \\
2.5 & \mathrm{E}(-3) \\
1.0 & \mathrm{E}(-4)\end{array}$ \\
\hline
\end{tabular}


TABLE 3

H1501/W48

CH-47 Helicopter Discrete Frequency Excitation Amplitudes

\begin{tabular}{cccc} 
Frequency $(\mathrm{Hz})$ & Transv. amp (g) & Long. amp $(\mathrm{g})$ & Vertical amp $(\mathrm{g})$ \\
\cline { 2 - 3 } 12 & .20 & .28 & 1.00 \\
24 & .24 & .88 & 1.00 \\
36 & .18 & .20 & .31 \\
48 & .14 & .14 & .31 \\
60 & .12 & .18 & .62 \\
72 & .11 & .18 & .24 \\
84 & .12 & .18 & .16
\end{tabular}

TABLE 4

H1501/W79 Testing Sequence

$\begin{array}{ll}\text { Environment } & \text { Axis } \\ \begin{array}{l}\text { Random vibration } \\ \text { Sine divells }\end{array} & \text { Y (longitudinal) } \\ \text { Random vibration } & \text { Y } \\ \text { Sine dwells } & \text { X (transverse) } \\ \text { Random vibration } & \text { Z (vertical) } \\ \text { Sine dwells } & \mathrm{Z} \\ \text { Drop Test- 18" flat } & \mathrm{Z} \\ \text { Drop Test- 58" flat } & \mathrm{Z}\end{array}$


TABLE 5

H1501/W79 Random Vibration Spectra

Longitudinal $(\mathrm{Y})$ and

\begin{tabular}{|c|c|c|}
\hline Transverse (X) Axes & Frequency $(\mathrm{Hz})$ & $\operatorname{ASD}\left(\mathrm{G}^{2} / \mathrm{Hz}\right)$ \\
\hline & $\overline{5}$ & .0001 \\
\hline & 10 & .0065 \\
\hline & 20 & .0065 \\
\hline & 50 & .0010 \\
\hline & 120 & .0010 \\
\hline & 130 & .0030 \\
\hline & 200 & .0030 \\
\hline & 250 & .0010 \\
\hline & 1000 & .0010 \\
\hline & 1900 & .0001 \\
\hline \multirow[t]{9}{*}{ Vertical ( $Z$ ) Axis } & 5 & .0001 \\
\hline & 10 & .0150 \\
\hline & 40 & .0150 \\
\hline & 100 & .0025 \\
\hline & 200 & $.0(010$ \\
\hline & 350 & $.0(0) 35$ \\
\hline & 5()() & .0035 \\
\hline & 1000 & $.0(025$ \\
\hline & 190() & .0001 \\
\hline
\end{tabular}

TABLE 6

H1501/W79 Sine Dwell Testing

Longitudinal $(Y)$ and

Amplitude

Transverse $(X)$ Axes

Frequency $(\mathrm{Hz})$

(0-to-peak g)

\begin{tabular}{lcc}
\hline & 11 & 0.5 \\
& 22 & 0.5 \\
Vertical (Z) Axis & 11 & 1.0 \\
& 22 & 0.5
\end{tabular}




\section{REFERENCES}

1. Final Development Report H1501 Special Transportation Container (U), R. M. Hargreaves, SAND 87-8023, RS 8162/1454, October 1987

2. HARC Scale Model Fuel Burn Test, R. L. Ledgerwood, SAND 74-0302, December 1974

3. HARC 3/8 Scale Sympathetic Detonation Test, M. G. Vigil, R494108, October 1972

4. Final Development Report- Helicopter Accident Resestand Container (HARC) (U), T. K. Hill, R. L. Ledgewood, SAND 76-0586, RS 3151/172, January 1977

5. Personal Communication, J. W. Liebenberg 5365, to Distribution, April 1991

6. Personal Communication, S. S. White 8162 , to Distribution, May 26, 1987

7. Personal Communication, S. S. White 8162, to Distribution, December 1, 1990 


\section{UNLIMITED RELEASE}

\section{INITIAL DISTRIBUTION:}

U. S. Department of Energy Albuquerque Operations Office Attn: H. T. Season Jr., Director WPD

A. E. Whiteman, Director WQD

M. C. Baca, WPD

K. L. Smithson, WPD

P. O. Box 5400

Albuquerque, NM 87115

U. S. Department of Energy

Kansas City Area Orfice

Altn: C. C. Ross

P. O. Box 419159

Kansas City, MO 64141-6159

U. S. Department of Energy

Field Office, Oak Ridge

Attn: Central Library

For: S. A. Watkins, QL

P. O. Box 2001

Oak Ridge, TN 37831-8764

Allied-Signal Inc. (3)

Altn: V. E. Alley, D/005

R. G. Gemeinhardt, D/005

G. V. Robbins, D/005

P. F. Ross, D/231

D. C. Steinke, D/231 (1D40)

W. G. Cooper, D/800

C. E. Bushey, D/811

D. W. Carlson, D/811 (2A36)

D. S. Douglas, D/811

P O Box 419159

Kansas City, MO 64141-6159

Allied-Signal Inc. (2)

Attn: E. F. Kibalo, D/005

P O Box 419159

Kansas City, MO 64141-6159 
2700 R. A. David

Attn: T. L. Workman, 2761

5000 R. L. Hagengruber

Attn: H. J. Saxton, 5400

C. S. Yarnall, 5500

D. B. Hayes, 5600

J. L. Wirth, 5800

5100 W. C. Nickell

Attn: J. O. Harrisnn, 5115

5300 J. B. Wright

Attn: E. T. Cull, 5354

M. H. Reynolds, 5361

C. A. Pura, 5362

D. J. Beyer, 5363

R. G. Miller, 5366

D. R. Henson, 5371

C. T. Oien, 5375

5365 G. C. Story, 5365 (2)

8000 J. C. Crawford

Attn: E. E. Ives, 5200

M. E. John, 8100

R. J. Detry, 8200

L. A. Hiles, 8400

P. E. Brewer, 8500

L. A. West, 8600

R. C. Wayne, 8700

8535 Publications for OSTI (10)

8535 Publications/Technical Library Processes, 7141

7141 Technical Library Processes Division (3)

8523-2 Central Technical Files (3) 

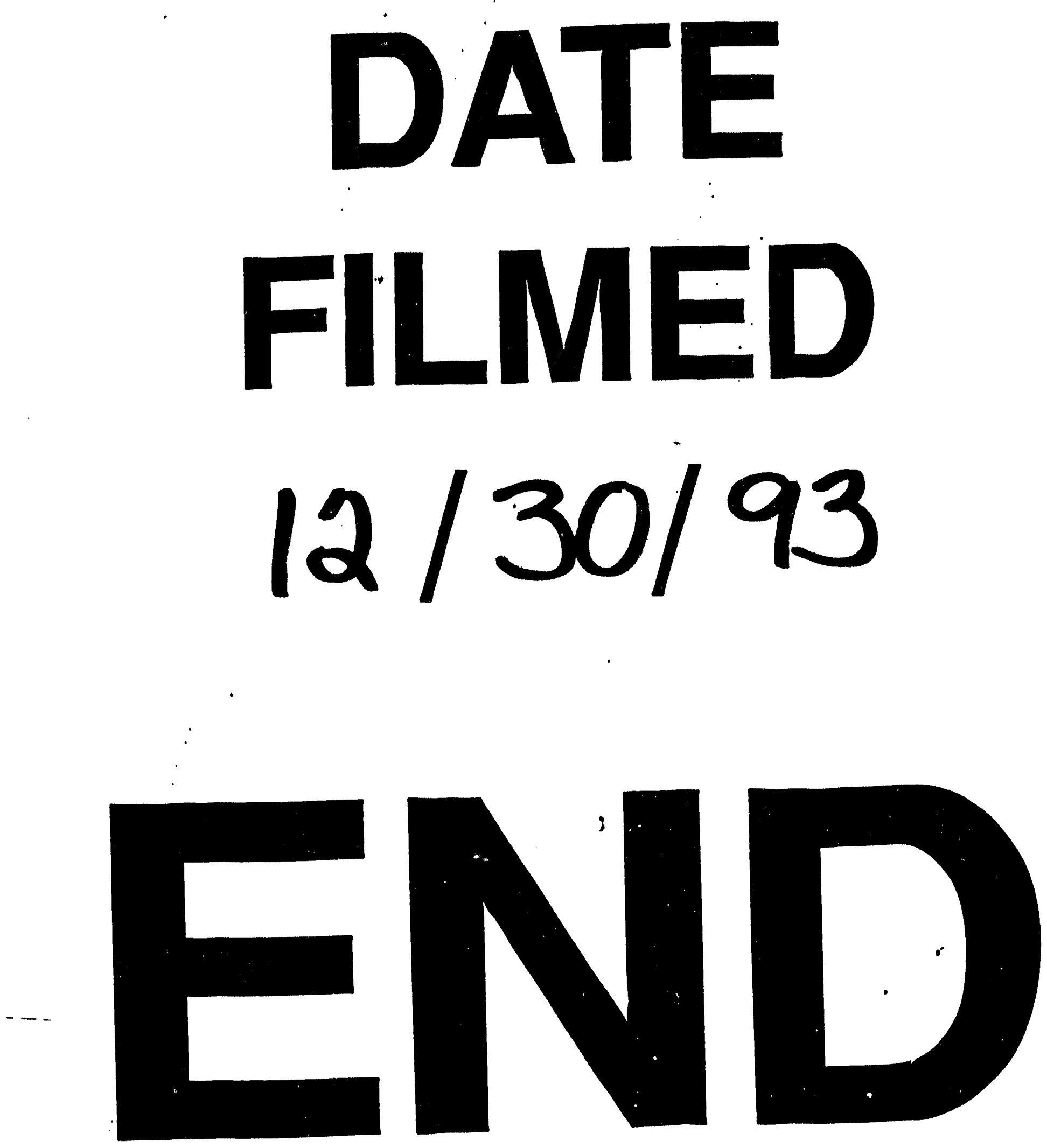
